\title{
O VALOR DE UM AFETO: AFETIVIDADE NA EDUCAÇÃO INFANTIL
}

\author{
THE VALUE OF AFFECTION: AFFECTIVITY IN EARLY CHILDHOOD EDUCATION
}

\author{
Eliane Holzlechner Taube
}

Professora da Rede Municipal de Ensino de Ijuí, Ijuí, RS, Brasil. E-mail: elianeht@hotmail.com

DOI: https://doi.org/10.46550/amormundi.v2i6.124

Recebido em: 20.08.2021

Aceito em: 08.10.2021

\begin{abstract}
Resumo: $\mathrm{O}$ trabalho educacional envolvendo a afetividade é um assunto importante para a educação infantil. Nesse sentido, é preciso reconhecer o valor deste sentimento, e como ele auxilia no desenvolvimento cognitivo, psicológico, físico, afetivo e social de maneira prazerosa. Portanto, é necessário ter conhecimento de como ocorrem os processos de ensino e aprendizagem na educação infantil e assim mediar as açóes educativas na busca de uma educaçấo plena e de qualidade.
\end{abstract}

Palavras-chave: Afetividade. Aprendizado. Desenvolvimento. Sentimentos. Segurança.

Abstract: Educational work involving affectivity is an important issue for early childhood education. In this sense, it is necessary to recognize the value of this feeling, and how it helps in the cognitive, psychological, physical, affective and social development in a pleasurable way. Therefore, it is necessary to have knowledge of how the teaching and learning processes occur in early childhood education and thus mediate educational actions in the search for full and quality education.

Keywords: Affection. Apprenticeship. Development. Feelings. Safety.

\section{Introdução}

A feto é muito mais que dar carinho. É ter paciência e transmitir segurança, é saber ter personalidade e temperamento, é ter paixão, amor e emoção pelo outro. Afetividade não se resume em família, parentes, amigos e vizinhos, mas também precisa estar presente num ambiente escolar, entre professores e alunos, importantíssimo em todas as relaçóes de sentimentos, memória, autoestima e pensamento.

Destacando que a afetividade familiar é a primeira manifestação que acontece com as crianças, contribuindo plenamente para o seu desenvolvimento. No entanto este processo de desenvolvimento não pode terminar quando a criança começa a frequentar uma instituição escolar e sim continuar em todo o seu âmbito educacional.

Professores ou docentes são aquelas pessoas que fazem parte do desenvolvimento do ser 
humano, que orientam a todos abrindo caminhos para que possam viver em sociedade. Que passam muito mais que conteúdo, que entendam o seu aluno e lhe ajudam a encontrar os seus objetivos.

A temática escolhida além de ser importante no desenvolvimento, também irá trabalhar outros conhecimentos, tais como a motricidade, através das brincadeiras, o gosto pela leitura, através das historinhas, estimular a imaginação das crianças fazendo com que possam expressar suas emoçóes e seus sentimentos, enfim habilidades necessárias para o seu cotidiano, tanto escolar como social.

E pensando neste muito mais que só passar conteúdo que entra o tema do texto, "afetividade na educação infantil". Embasado numa história que consta a importância de um abraço, englobado com diversas atividades que desenvolvem a afetividade, o coleguismo, a motricidade ampla, o raciocínio, bem como diferentes tipos de linguagem oral e corporal.

A avaliação acontece na observação individual de cada um com registros e reflexôes, relatando as dificuldades e os avanços em cada área, acompanhado com seu desempenho e seu desenvolvimento através de registros, pareceres e fichas de anotaçóes com fatos observados durante a atuação.

O escrito baseia-se em um estudo, como também em um momento de observação, percebendo o quáo importante se faz o afeto na vida de uma criança para o seu desenvolvimento pessoal, transmitindo segurança, autoconfiança, construindo o seu eu, com prazer e grande desejo de aprender, assim, baseia-se em grandes pensadores como Wallon, Vigotski, Piaget Gadotti e Paulo Freire, que trazem informaçôes sobre a importância deste sentimento no processo de aprendizado na educaçáo infantil. O referido escrito vem ao encontro dos assuntos estudados no período da formação acadêmica, culminando esta formação e abrangendo assuntos pertinentes a esta formação profissional.

\section{Revisão bibliográfica}

Afeto, sentimento este que está exigindo uma grande reflexão nos últimos tempos, principalmente por parte dos educadores, que precisam ser o elo desta corrente, mesmo sabendo que a escola deve investir nos três aspectos: cognitivo, afetivo e psicomotor. A interaçáo entre o afeto e a cogniçáo é o que fundamenta o entendimento de um desenvolvimento integral do ser humano.

O ser humano é movido pela afetividade, tanto no aspecto positivo quanto para o negativo, tendo nos dois casos como afetividade um elemento de criar mecanismos de compreensão, aceitação, defesa e administração de sensaçóes. Considerando que a aprendizagem se da através do processo de ensino- aprendizagem, sendo que um depende do outro nas interaçóes, nas trocas de conhecimento e no convívio e que para tal processo o melhor intermediário desta vivencia é afetividade.

O docente através da afetividade e da capacidade psicológica de tentar entender os sentimentos e emoçôes das crianças, irá conquistar o aluno e só depois irá passa o conhecimento, pois o que marca na vida da criança será o que foi feito com amor, carinho, atenção e afeto, e não o que foi feito com ódio e raiva. A relação afetiva é contemplada com cargas positivas, marcando a aquisição do conhecimento e contribuindo na autonomia e na confiança de tomada 
de decisões. Compreender o mundo real pela sensibilidade e reflexão, através do pensar, do sentir, do imaginar e do agir, fundamentam - se para estar nele em um campo real.

Refletir este processo:

É compreender que a vida afetiva - emoçôes e sentimentos - compóe o homem e constitui um aspecto de fundamental importância na vida psíquica. As emoções e sentimentos são como alimentos de nosso psiquismo e estão presentes em todas as manifestaçôes de nossa vida. Necessitamos deles porque (...) orientam-nos e nos ajudam nas decisōes (BOCK; FURTADO; TEIXEIRA, 1999, p. 198).

O professor precisa apresentar um amor individual e coletivo, deixando muitas vezes seus desejos e vontades de lado, para buscar as necessidades do desenvolvimento da própria criança, guiando seu comportamento e provando um senso de humor oportuno e necessário. Diga-se que o professor é o mediador, queira ele ou não! Ele servirá de modelo na sua forma de ser, de se expressar, de resolver as situaçóes, de se comunicar, de falar, de ouvir e de se relacionar com os outros, sendo com os professores, os alunos, funcionários e direção. Não que ele seja o único responsável, mas que seja mais um, tanto como pessoa, tanto como profissional.

Ele precisa tomar a sério sua condição de escultor de sensibilidade. Assim como se entrega ao artista o mármore ou a tela para que crie uma obra de arte, a nós nos oferecem diariamente seres humanos para interagirmos e cultivarmos com eles climas de sensibilidade que permitam alcançar um estado estético favorável à plena expressão das singularidades (RESTREPO, 1998, p. 81).

Em tempos descobrimos a importância do afeto entre professores e alunos, indispensável para o desenvolvimento da criança, que precisa encontrar no docente um amigo, um companheiro, aquele que lhe passe segurança e lhe ajude em todos os momentos e que não seja o detentor da verdade, mas sim que coloque em prática o diálogo importantíssimo para a relação entre ambos.

O Educador para por em pratica o diálogo não deve colocar-se na posição de detentor do saber, deve antes, colocar-se na posição de quem não sabe tudo, reconhecendo que mesmo um analfabeto é portador do conhecimento mais importante: o da vida (GADOTTI, 1999). A afetividade passa por todo o processo educacional e, muitas vezes preocupam-se tanto com conteúdos e métodos modernos para este ato, esquecendo do diálogo, táo importante para o laço afetivo de ambos, criando até laços tão profundos que serão eternos. Sendo esta relação o sucesso ou o fracasso de uma criança.

Segundo Almeida (2001), a afetividade, assim como a inteligência, não aparece pronta permanece imutável. Ambas evoluem ao longo do desenvolvimento: são construídas e se modificam de um período a outro à medida que o indivíduo se desenvolvem, as necessidades afetivas se tornam cognitivas.

A afetividade acontece em todo âmbito escolar, mas é na educação infantil que a relação professor e aluno são mais constantes e acontece a todos os momentos, tanto em sala de aula como nas atividades de brincadeiras em pátio. É nesta aproximidade que se dá a interação aos objetos e a construção do conhecimento.

Saltini (2008, p. 100) afirma que, "essa inter-relação é o fio condutor, o suporte afetivo do conhecimento". O referido autor complementa:

Neste caso, o educador serve de continente para a criança. Poderíamos dizer, portanto, que o continente é o espaço onde podemos depositar nossas pequenas 
construçôes e onde elas são acolhidas e valorizadas, tal qual um útero acolhe o embrião. A criança deseja e necessita ser amada, aceita, acolhida e ouvida para que possa despertar para a vida da curiosidade e do aprendizado. (SALTINI, 2008, p. 100).

Estabelecer com as crianças laços afetivos, estético, social e político, será possível muitas vezes se viabilizarmos por meio de reflexóes, histórias e narrativas que as crianças fazem acerca de suas vivências. A afetividade também é deixar a criança à vontade para colocar suas dificuldades, mantendo uma amizade com a mesma para que não tenha medo de errar, mas sim que possa confiar no professor, como o qual ajudará a encontrar o caminho. $\mathrm{O}$ afeto até mesmo pode ser representado através de uma crítica, fazendo com que nasce o contato entre a vida e a realidade.

Devido a um apego a cultura, existe um medo por parte dos professores em demonstrar a afetividade aos seus alunos, pois podem perder a sua autoridade perante aos mesmos. Pequenos gestos como um sorriso, um olhar, o respeito, o escutar, o ter paciência de ajudar e ensinar quando não se sabe, pode fazer a diferença entre esta relação. Saltini (2008, p. 100) afirma que "essa inter-relação é o fio condutor, o suporte afetivo do conhecimento".

Dar atenção ao aluno importar-se e preocupar-se com ele, gera aproximidade com uma consequência de solidariedade, abrindo novas oportunidades de aprendizado. E nestas novas oportunidades não contemplará somente o aluno, mas sim o professor que também necessita desta troca de afeto, para sentir-se bem recebido e aceito, fazendo que ambos tenham sucesso neste processo. Para a identificaçáo do seu eu, existem sentimentos indispensáveis neste reconhecimento, e a escola se tornou um fator importante para transpor estes elementos com o apoio e o afeto. Todos sabem que temos dificuldades, e assim também é com as crianças elas precisam de apoio e afeto para identificar-se e dispor-se de todas as tarefas.

Às vezes mal se imagina o que pode passar a representar um simples gesto de um professor. $\mathrm{O}$ que pode um gesto aparentemente insignificante valer como força formadora ou como contribuição à do educando por si mesmo. (FREIRE, 1999, p. 47). Além de ser um sentimento, o afeto também é uma forma de comunicação entre o ser humano, um abraço, um sorriso pode demonstrar o quanto aquele ser é importante para nós e que existe um laço de afetividade que permeia a nossa relaçáo.

Afeto também é respeitar um ao outro. Sentir-se respeitado em suas diferenças e dificuldades, gerando respeito e aceitação aos outros também, tanto aos professores como aos seus colegas. A afetividade gera aproximidade e em consequência a solidariedade. Ser solidário é estender a mão a quem precisa nas dificuldades, é estar ao seu lado mostrando-lhes o caminho.

Segundo Alícia Fernandes, a exclusão do afeto no processo educativo vai definir o que vai acontecer na sala de aula, se os alunos aprenderão ou náo. Tratar o aluno com beijinhos ou agradá-lo. Ela diz: "a indiferença é a falta de afetividade. Você fica sem a possibilidade de sentir alguma coisa diante do que acontece no mundo. Você se posta na vida como um objeto e não como um sujeito e objetos, ao contrário dos sujeitos, não têm afetividade" (2005, p. 23).

Repensar uma nova dinâmica do espaço e das relaçóes em um campo afetivo e solidário pode trazer melhores resultados. O aluno precisa de estímulos, de elogios, de aprovação e de aceitação para se pré-dispor a fazer as tarefas e exigências que lhes é imposta. Apesar dos avanços científicos e tecnológicos, a pedagogia afetiva teria que ter destaque, valorizando as amizades, o carinho, a socialização, o respeito, o afeto, a solidariedade e a emoção. 
Para Cury (2003, pp. 97-109), a educação do afeto deve ser a meta de todo educador; os educadores que não provocam a emoçáo das crianças não educam, apenas informam, assim como dar conselhos e orientaçôes sem emoção na gera momentos educacionais. Para WALLON a afetividade é expressa em três maneiras, sendo elas pela emoção, pelos sentimentos e pela paixão. Manifestaçôes que surgem durante toda a vida do indivíduo.

Wallon (apud LA TAILLE, 1992) em sua teoria da emoção, considera a afetividade e inteligência fatores misturado, e defende que a educação da emoção deve ser incluída entre os propósitos da ação pedagógica. Educar não é um fato isolado, mas coletivo quando feito com amor e sentimentos, isto é um ato de humanização, de libertação ou como fala Edgar Morin: "A educação deve favorecer a aptidão natural da mente em formular e resolver problemas essenciais, de formar correlata, estimular o uso total da inteligência" (2000, p. 39).

Já nos primeiros meses de vida o afeto tem a função de comunicação como WALLON (1968) defende que no decorrer de todo o desenvolvimento do indivíduo, a afetividade tem um papel fundamental. Tem a função de comunicaçáo nos primeiros meses de vida, manifestandose, basicamente, através de impulsos emocionais, estabelecendo com a criança e com o mundo.

Pode se falar que a escola é a continuação da vida familiar e é importante que a criança se sinta bem acolhida e entenda que a separaçáo é um processo natural e que comece a criar dentro de si a noção de responsabilidade, sendo assim, não se limita em conhecimentos conceituais, mas sim no desenvolvimento de seus alunos na sua totalidade.

Segundo Wallon (apud Dantas, 1992), a afetividade é anterior ao desenvolvimento, e as emoçóes têm papel predominante no desenvolvimento da pessoa, é por meio delas que o aluno exterioriza seus desejos e suas vontades. Pode se disser que afetividade é o ponto de partida para o desenvolvimento do indivíduo. Ponto de partida que será a base para a sua formação. Formação que se inicia já no âmbito familiar, sendo que a partir dali a criança vivencia e/o vivenciou este ponto chamado afeto, capacitando assim à forma de encarar, resolver e enfrentar os problemas da vida seja na escola ou fora dela

Wallon (1995), define a evolução do ser humano através de estágios comportamentais, aonde a criança vai vivenciando diversas situaçôes e isso vai contribuir para o seu crescimento. Como a criança evolui até tornar-se adulta, do ponto de vista afetiva. Em um mundo táo cheio de exclusôes e violência, ajudar as pessoas a encontrar um sentido em suas vidas, ajudar que sejam inclusas, mesmo com todas as diferenças, possibilita um sentido que as humanize.

O médico psiquiatra e escritor Shinyashiki em seu livro "A caricia Essencial" fala de quão importante é o estimulo tátil e afetivo da família para a criança, além de proporcionar aprazibilidade, traz segurança e proteção auxiliando o indivíduo na criação de sua identidade. Estudos do psicanalista americano René Spitz sobre os efeitos negativos da falta de contato físico nas crianças doentes e conclui que:

Uma criança sem carinho - contato físico -, apesar de todo o tratamento médico, pode náo sarar, por estar mantendo uma doença oriunda de afagos. A criança necessita ser tocada, beijada, olhada, percebida (SHINYASHIKI, 1985, p. 29).

Boff (1999 p. 171) expressa claramente o poder carícia: "a mão que toca cura porque leva carícia, desenvolve confiança, oferece acolhida e manifesta cuidado. A mão faz nascer à essência humana naqueles que são tocadas". A afetividade também é o ponto chave para a adaptação das crianças já nos primeiros dias de aula, é com este sentimento de afeto, de aconchego, de 
acolhimento que se conseguirá a confiança, passando segurança com a sua presença.

Para conhecer os alunos a melhor opção é se aproximar deles com muito carinho e amor, é ser amigo e ouvinte, ser um aliado neste processo de ensino e aprendizado, saber que além de corpo o aluno possui sentimentos, desejos, problemas e frustraçôes. O interesse, a curiosidade, as dúvidas, os medos encontram na afetividade maneiras para se expressar, passando segurança e apoio na busca do conhecimento do mundo e de si mesma.

Adquirindo confiança e segurança a criança irá compartilhar as suas dificuldades fazendo com que torne mais fácil de saber como ajudar e ensinar a mesma para o seu desenvolvimento. Confiança é tudo para o aluno, é uma ferramenta para o sucesso na conquista do educando, tornando-se um referencial, um orientador e auxiliador de suas conquistas.

A conquista além de ser muito importante para o aluno, também é muito importante para o professor que se sente realizado quando percebe que conseguiu passar seu ensinamento com tranquilidade, amizade e serenidade, sem castigos e puniçóes. Silva (2001) enfatiza a importância do professor para que os alunos se sentem mais seguros criando, assim, um ambiente de aprendizado tranquilo, pois a afetividade se faz presente no cotidiano da sala de aula, seja na postura do professor, pela dinâmica de seu trabalho ou nas interaçóes entre sujeitos.

Através da afetividade, tornaremos a escola um local prazeroso e desejado de se ir, respaldados pela liberdade, pelo respeito e pela união tornando um encontro agradável entre duas pessoas e dois desejos. Anulando assim aquele local indesejado e pronto para se livrar dos estudos de uma vez. Um ambiente afetivo em sala de aula incentiva o aprender. Torna-se um espaço em que o aluno aprende a sonhar, alargando novos horizontes, desejos e as necessidades, tornando seres criativos, ternos e solidários. Diga-se que a afetividade está ligada a diversos termos, sendo eles relacionados com a emoção, estados de humor, motivação, sentimentos, paixão, atenção, personalidade, temperamento, inteligência entre outros.

Além do afeto professor e aluno, cabe ressaltar a importância do afeto entre os colegas e amigos, socializando o companheirismo, a amizade o respeito um com o outro, tornando um local acolhedor e seguro para todos.

O professor pode criar um ambiente que oportunize aos alunos a desenvolver a sua afetividade através de um aperto de mão, acariciar a cabeça, o rosto, passar a mão nas costas, pegar na máo, gestos estes que muitas vezes nấo fazem parte do dia- a- dia da escola.

O tato na escola muitas vezes tem pouco lugar e não é reconhecido nos ambientes escolares, dentro dos esquemas pedagógicos. De acordo com Restrepo (1998 p. 34).

Ao excluir o tato e o olfato do processo pedagógico, nega-se a possibilidade de fomentar uma intimidade e proximidade afetiva com o aluno, perpetuando-se uma distancia corporal que reforça a aproximaçáo de poder do mestre, que agora se torna se torna verdade incontestável. Este manejo do espaço nega sumariamente ao estudante a possibilidade de reconstruir a dinâmica afetiva dos conteúdos cognoscitivos que lhe são entregues, mutilando assim o saber e perpetuando- se o autoritarismo.

Náo basta querer que o sentimento da afetividade apareça dentro de uma sala de aula, é preciso criar alternativas oportunizando este momento. E uma das maneiras de oportunizar este momento é o lúdico o qual está intimamente ligado a infância. O lúdico é uma ferramenta metodológica eficaz na busca de uma boa educação, e é natural da criança gostar de brincar, 
cantar, jogar, correr, deitar, rolar, e se encantar com o faz de conta, utilizando assim a melhor maneira de potencializar a aprendizagem e o afeto na educação infantil.

Vigotski (1998) divide o desenvolvimento em dois níveis. O primeiro é o nível de desenvolvimento real, é tudo aquilo que a criança consegue fazer sozinha. $\mathrm{O}$ segundo seria o nível de desenvolvimento potencial, ou seja, o que a criança não realiza sozinha, porém com a ajuda de um adulto ou um parceiro mais capaz que ela, conseguindo assim realizar. É no segundo nível que entra o papel do professor ajudando e criando oportunidades para que a criança desenvolva este sentimento tão importante para o ser humano até mesmo na adolescência.

$\mathrm{Na}$ educação infantil primeira etapa da Educação Básica, que tem como finalidade o desenvolvimento integral da criança, conforme a LDB- lei de Diretrizes e Bases da Educação Nacional (Lei Federal no 9394/96). Para ter sucesso como educador e fazer a diferença, será preciso considerar que muito mais que ensinar, é preciso desenvolver o papel em torno do cuidado, da atenção e do acolhimento, da alegria, da brincadeira, do afeto, do cuidar, e do que é importante para eles.

A serenidade e a paciência do docente, mesmo em situaçóes difíceis, faz parte do que a criança necessita. Controlar a ansiedade e a instabilidade do humor vai assegurar a criança o controle de seus próprios conflitos e raivas, tanto sozinhas ou em conjunto com o educador. A serenidade faz parte do conjunto de sensaçóes e percepções que garantem a elaboração de nossas raivas e conflitos. Ela conduz ao conhecimento de nós mesmos, tanto do educador quanto da criança (SALTINI, 1997).

Wallon (apud Almeida, 1999) destaca que "a afetividade e a inteligência constituem um par inseparável na evolução psíquica, pois ambas têm funçôes bem definidas e, quando integradas permitem à criança atingir níveis de evolução cada vez mais elevadas". A relação professor e aluno dependem do clima e da relação de empatia que será estabelecido entre ambos. A capacidade de ouvir, refletir, discutir, respeitar, aceitar e entender cria uma ponte entre ambos relacionando o seu conhecimento com os dos outros englobando o lado positivo para a formação de um cidadáo consciente de seus deveres e suas responsabilidades. Educar é ensinar a olhar para fora e para dentro, superando o divórcio, típico da nossa sociedade, entre a objetividade e a subjetividade. É aprender além é saber que é tão verdade que, a menor distância entre dois seres humanos, é o riso e a lágrima (ALENCAR, 2001).

\section{A afetividade sob óptica piagetiana}

$\mathrm{Na}$ ótica piagetiana, o afeto desempenha um papel essencial no funcionamento da inteligência, pois segundo Piaget: "vida afetiva e vida cognitiva são inseparáveis, embora distintas". Ambas são inseparáveis em todo o intercâmbio entre valorização e estruturação. Salientando que sem afeto não há interesse, não há necessidade, e nem motivação pelo aprendizado, também não há questionamentos e nem desenvolvimento mental. Enfim afetividade e cognição se complementam dando suporte um para o outro. $\mathrm{O}$ afeto, segundo Piaget, pode acelerar ou retardar a formação das estruturas cognitivas. Embora condição necessária, só o afeto não é condiçãoo suficiente para a formação das mesmas.

Em seis estudos de psicologia (1986), Piaget enfatiza mais uma vez que existe um paralelo constante entre a vida afetiva e a intelectual, e que esse paralelismo continuará por 
todo desenvolvimento até a adolescência. Afetividade e inteligência são assim indissociáveis e constituem os dois aspectos complementares de toda conduta humana (PIAGET, 1986, p. 22).

\section{Afetividade em Paulo Freire}

Às vezes mal se imagina o que pode passar a representar um simples gesto de um professor. O que pode um gesto aparentemente insignificante valer como contribuição à do educando por si mesmo (FREIRE, 1999, 47).

É fundamental que na prática da formação docente, o aprendiz de educador assuma que o indispensável pensar certo não é presente dos deuses nem se acha nos guias de professores que iluminados intelectuais escrevem desde o centro de poder, mas pelo contrário, o pensar certo, que supera o ingênuo, tem que ser pelo próprio aprendiz em comunhão com o professor formador. Por isso o momento fundamental é o da reflexão crítica sobre a prática. (FREIRE, 1999, p. 43).

\section{Afetividade em Henri Wallon}

Grandes estudiosos atribuíram na importância da afetividade no processo evolutivo, mas foi o educador francês Henri Wallon (1879-1962) que se aprofundou mais nesta questão. Ele nos coloca que a inteligência náo é o fator principal no desenvolvimento do ser humano e sim a vida psíquica formada pelas três dimensões. Motora, afetiva e cognitiva.

Ele destaca a alternância existente entre a função cognitiva e afetiva, sendo eles entrelaçada uma com a outra e não acontecendo em separadas, mas uma sempre se sobre sai a outra. Afirma também que não se pode separar a afetividade da cognição, sendo vital em todos os seres humanos.

Na psicogenética de Henri Wallon (apud LA TAILLE 1992), a dimensão afetiva está no centro de tudo, tanto do ponto de vista da construção da pessoa quanto ao conhecimento. Para ele a afetividade é fator fundamental no desenvolvimento da pessoa, é por meio dela que o aluno exterioriza seus desejos e suas vontades.

O afeto é essencial para todo o funcionamento do nosso corpo, nos dando coragem, motivação, interesse e contribuindo para nosso desenvolvimento. E é pelas sensaçóes que o afeto nos proporciona que sabemos quando algo é verdadeiro ou não. Principalmente para a criança o afeto é importantíssimo, pois ela precisa sentir-se segura para poder desenvolver seu aprendizado, e é necessário que o professor tenha consciência de como seus atos são extremamente significativos nesse processo, porque esta relação aluno- professor é permeada de afeto, e as emoçôes são estruturantes da inteligência do indivíduo (WALLON, 1995).

\section{Consideraçóes finais}

Em consideração e conforme os pensadores citados neste estudo, inúmeras são as colocaçóes importantes e o esclarecimento de muitas dúvidas, obviamente colaboram para o crescimento profissional e pessoal. É possível salientar o quão importante se torna o afeto na vida de um ser, aqui, principalmente, na educação infantil, tornando-se quase que indispensável para o seu desenvolvimento. 
A afetividade além de ser muito importante, melhora e muito o trabalho do docente que vai ter no aluno um amigo, um companheiro, mostrando suas alegrias e tristezas, suas dificuldades e o seu progresso.

O trabalho com esta harmonia será prazeroso para ambos os lados, tanto para o professor como para o aluno. Será um lugar de crescimento mútuo, aberto a opinióes e ideias, tornando-se um verdadeiro ensinar e aprender.

\section{Referências}

BRASIL, Ministério da Educação e do Desporto. Referencial Curricular Nacional para a Educação Infantil. Disponível em: http://portal.mec.gov.br/seb/arquivos/pdf/rcnei_vol1. Acesso em: 20 mar. 2021.

EMILIANO, Joyce Monteiro; TOMÁS, Débora Nogueira. Vigotski: a relação entre afetividade, desenvolvimento e aprendizagem e suas implicaçôes na pratica docente. Cadernos de Educação: Ensino e Sociedade, Bebedouro-SP, 2 (1): 59-72, 2015.

FROZZA, Iris. Aprendizagem e Afetividade: um encontro de sucesso na escola, UNOESC/ Joaçaba, 2007.

FREIRE, P. Pedagogia do Oprimido. Rio de Janeiro: Paz e Terra, 1999.

PESSOA, Vilmarise Sabim. A afetividade sob ótica psicanalítica e piagetiana. Publicatio. v.8, n. $1,2000$.

VIGOSTKI, L. S. Teoria e Método em Psicologia. São Paulo: Martins Fontes, 2004.

WALLON, H. Afetividade e aprendizagem: Contribuiçóes de Henry Wallon. Sáo Paulo: Edições Loyola, 2007. 